\title{
$1-{ }^{11} \mathrm{C}-$ Methyl-4-Piperidinyl- $N$-Butyrate Radiation Dosimetry in Humans by Dynamic Organ-Specific Evaluation
}

\author{
Jere R. Virta ${ }^{1}$, Tuula Tolvanen ${ }^{1}$, Kjell Någren ${ }^{2}$, Anna Brück ${ }^{1}$, Anne Roivainen ${ }^{1}$, and Juha O. Rinne ${ }^{1}$ \\ ${ }^{I}$ Turku University Hospital, Turku PET Centre, Turku, Finland; and ${ }^{2}$ Radiopharmaceutical Chemistry Laboratory, Turku PET Centre, \\ Turku, Finland
}

Deficits of cholinergic neurotransmission contribute to various neurologic and psychiatric conditions. The neurotransmitter acetylcholine is hydrolyzed in the synaptic clefts by 2 enzymes, acetylcholinesterase (AChE) and butyrylcholinesterase (BuChE). $1-\left[{ }^{11} \mathrm{C}\right]-$ Methyl-4-piperidinyl- $N$-butyrate $\left({ }^{11} \mathrm{C}-\mathrm{MP} 4 \mathrm{~B}\right)$ is a radioligand for the assessment study of BuChE activity in human brain with PET. In the present study the radiation-absorbed doses of the ${ }^{11} \mathrm{C}-\mathrm{MP} 4 \mathrm{~B}$ were estimated in humans according to the guidelines of the International Commission on Radiological Protection. Two different data acquisition protocols — dynamic organ-specific evaluation (DOSE) and whole-body scanning - were compared. Both methods are widely used for evaluation of radiation burden of ${ }^{11} \mathrm{C}$-labeled PET tracers. Methods: Fixed-bed PET on the upper neck, thorax, abdomen, or pelvic region was performed on 7 healthy subjects after injection of $707 \pm 34 \mathrm{MBq}$ (mean $\pm \mathrm{SD}$ ) of ${ }^{11} \mathrm{C}-\mathrm{MP} 4 \mathrm{~B}$. Brain input was derived from our previous studies on 18 healthy control subjects and 10 patients with Alzheimer's disease. Regions of interest were drawn on transverse images of all visible organs. Radiation dose estimates were calculated from organ residence times using the MIRDOSE3 software. Urine samples were collected after imaging to estimate tracer extraction. To compare the estimates for absorbed doses between the whole-body scan approach and the DOSE method, we simulated whole-body data acquisition methods used in ${ }^{11} \mathrm{C}$ dosimetry studies with our fixed-bed data. Results: The organs with the highest radiation-absorbed doses were the liver, urinary bladder, kidneys (renal cortex), upper large intestine, trabecular bone, salivary glands, and heart wall. Up to $60 \%$ of the injected dose was excreted via the urinary pathway, and the clearance was relatively rapid, as $30 \%$ of the radioactivity was excreted within 60 min after injection. With a 2-h voiding interval the effective dose was $4.2 \mu \mathrm{Sv} / \mathrm{MBq}$. Conclusion: ${ }^{11} \mathrm{C}-\mathrm{MP} 4 \mathrm{~B}$ causes less radiation burden than previously studied ${ }^{11} \mathrm{C}$-labeled $\mathrm{PET}$ tracers. No intolerably high absorbed doses were observed in critical organs. With $740 \mathrm{MBq}$ of injected radioactivity, the radiation burden is equivalent to $3.11 \mathrm{mSv}$. This would allow multiple PET examinations per year to be performed on the same subject. The DOSE method and the simulated whole-body imaging approach produced similar results.

Received Sep. 11, 2007; revision accepted Nov. 26, 2007.

For correspondence or reprints contact: Jere R. Virta, MD, Turku PET Centre, P.O. Box 52, FIN-20521, Turku, Finland.

E-mail: jere.virta@utu.fi

COPYRIGHT @ 2008 by the Society of Nuclear Medicine, Inc.
Key Words: butyrylcholinesterase; dosimetry; PET

J Nucl Med 2008; 49:347-353

DOI: 10.2967/jnumed.107.047233

D eficits in cholinergic neurotransmission contribute to various neurologic and psychiatric conditions (1). In Alzheimer's disease, especially, the mainstay of pharmacologic therapy is the enhancement of cholinergic neurotransmission (2) by inhibiting acetylcholinesterase (AChE) and butyrylcholinesterase $(\mathrm{BuChE})$, the enzymes hydrolyzing the neurotransmitter acetylcholine in the synaptic clefts. AChE has been considered the main target of anticholinesterase therapies, but increasing evidence suggests that BuChE has an important role in the pathophysiology of Alzheimer's disease (3-8).

PET is used to study the cholinergic system in vivo in human brain. Although PET radioligands assessing cerebral AChE activity are widely used (9-12), $1{ }^{11} \mathrm{C}-$ methyl-4piperidinyl- $N$-butyrate $\left({ }^{11} \mathrm{C}-\mathrm{MP} 4 \mathrm{~B}\right)$ is, to our knowledge, the first radioligand validated for the study of BuChE activity in human brain (13). It is the specific substrate for BuChE and is inert for AChE. The blood-brain barrier is impermeable to the hydrolyzed tracer ${ }^{11} \mathrm{C}-\mathrm{MP} 4 \mathrm{~B}-\mathrm{OH}$; thus, the tracer accumulates in the tissue in a rate determined by the local $\mathrm{BuChE}$ activity (14). Only a fraction of the injected tracer passes the blood-brain barrier, leaving most of the radioactivity in the lower parts of the body.

When assessing the risks of using radiopharmaceuticals against clinical benefits, the biologic risks of the internal radiation exposure are characterized by the effective dose. It is calculated by summing the absorbed doses in organs multiplied by a weighting factor, which accounts for the biologic effectiveness of different types of radiation in different organs. The common procedure for radiation dose calculations in nuclear medicine is the scheme developed by the MIRD Committee of the Society of Nuclear Medicine (15). In this approach, the characteristic distribution of the studied radiopharmaceutical (accumulation to "source organs"), physical characteristics of the radionuclide, and a specified anatomic model (phantom) are used to calculate absorbed doses in 26 
organs of the human body ("target organs") and in the rest of the body (tissues outside the target organs) (16).

We selected the source organs according to our previously published ${ }^{11} \mathrm{C}-\mathrm{MP} 4 \mathrm{~B}$ human biodistribution study (17) to cover the structures that receive a high radioactivity concentration after injection of the tracer and the structures known to be sensitive to adverse effects of ionizing radiation. The organs selected were brain, upper large intestine, heart content, heart wall, kidneys, liver, lungs, muscle (erector spinae), red bone marrow, cortical bone, trabecular bone, salivary glands (parotid and submandibular), and urinary bladder.

We measured the distribution of the tracer by dynamic, fixed-bed PET of selected body regions (dynamic organspecific evaluation, DOSE). The other widely used imaging method in radiation dosimetry studies is whole-body PET. We compared the results obtained by these 2 methods by simulating whole-body image acquisition with our fixed-bed data.

No radiation dose estimates have been previously described for ${ }^{11} \mathrm{C}-\mathrm{MP} 4 \mathrm{~B}$ or the other PET tracers for assessing the cholinergic nervous system in human brain. Evaluating the radiation exposure of this tracer is essential, as it is injected frequently to same subjects in follow-up and intervention studies. Accurately measured distribution and estimated radiation doses of ${ }^{11} \mathrm{C}-\mathrm{MP} 4 \mathrm{~B}$ can also be used as a reference when evaluating the risk-to-benefit balance of structurally similar PET tracers.

\section{MATERIALS AND METHODS}

\section{Subjects}

Biodistribution and residence times of ${ }^{11} \mathrm{C}-\mathrm{MP} 4 \mathrm{~B}$ were measured on 7 healthy young male volunteers from 21- to 24-y-old (mean age \pm $\mathrm{SD}, 23.4 \pm 0.8 \mathrm{y}$ ). PET was targeted to the abdominal region in 3 subjects to study liver, large intestine, kidneys, and skeletal muscle (erector spinae). Scanning was targeted to the thorax in 2 subjects to study heart, lungs, and liver. One subject was imaged in the pelvic area to study urinary bladder and red bone marrow in iliac cristae, and 1 subject was imaged in the upper neck area to study parotid and submandibular salivary glands. Brain data were obtained from our previous PET scans conducted primarily to evaluate the ${ }^{11} \mathrm{C}-\mathrm{MP} 4 \mathrm{~B}$ dynamics in dementing disorders. The brain data were pooled from 10 patients with Alzheimer's disease and 18 cognitively healthy subjects. Ten of the subjects were male and 18 were female. The mean age \pm SD of the subjects was $67.5 \pm 6.6$ y (age range, 58-80 y).

The studies were reviewed and approved by the Joint Committee of Ethics of the Turku University and Turku University Hospital and by the National Agency of Medicine. All participants gave their written informed consent before participating in this study. The participants with diagnosed dementing disorders were in an early stage of their disease and, thus, were able to give their informed consent autonomously.

\section{Dynamic PET Studies}

PET was performed with an Advance PET scanner (GE Healthcare). The scanner consists of 18 rings of bismuth germinate detectors, yielding 35 transverse slices spaced by $4.25 \mathrm{~mm}$. The imaging field of view (FOV) was $15.2 \mathrm{~cm}$ in axial length (18). Before injecting the tracer the radiation attenuation of the imaged area was measured with 2 rotating rod sources containing ${ }^{68} \mathrm{Ge} /{ }^{68} \mathrm{Ga}$. The scanner was operated in 2-dimensional (2D) mode for body imaging and in 3-dimensional (3D) mode for brain imaging. The 2D (high-resolution) mode was chosen to avoid the spillover effect, in which the organs having the high radioactivity concentration erroneously increase the radioactivity value in neighboring lower radioactivity organs. The radioactivity concentrations in abdominal organs are also high enough to challenge the scanner performance if 3D (high sensitivity) mode is used. Brain tissue is relatively homogeneous in tracer distribution and only a fraction of injected radioactivity passes the blood-brain barrier - thus, making the 3D mode an optimal choice for brain scanning.

The radiochemical synthesis and quality control of ${ }^{11} \mathrm{C}-\mathrm{MP} 4 \mathrm{~B}$ are described elsewhere (17). In short, the tracer was produced by the reaction of 4-butyryl-piperidine, generated in situ from its hydrochloride salt using 1,2,2,6,6-pentamethyl-piperidine, and ${ }^{11} \mathrm{C}$ methyl-triflate in methanol acetonitrile for $1 \mathrm{~min}$ at $60^{\circ} \mathrm{C}$. The crude product was purified using high-performance liquid chromatography (HPLC) with a $\mu$ Porasil column (Waters). After addition of 0.3 $\mathrm{mL}$ of sterile propylene glycol/ethanol $(7: 3 \mathrm{v} / \mathrm{v})$ and $100 \mu \mathrm{L}$ of 0.1 $\mathrm{mol} / \mathrm{L} \mathrm{HCl}$, the fraction containing the product was evaporated and redissolved in physiologic phosphate buffer $(0.1 \mathrm{~mol} / \mathrm{L}, \mathrm{pH} 7.4)$ and filtered through a $0.2-\mu \mathrm{m}$ Gelman Acrodisc 4192 sterile filter. Quality control was performed using HPLC with a Waters $\mu$ Bondapak C18 10- $\mu \mathrm{m}, 3.9 \times 300 \mathrm{~mm}$ column (Waters) and a gradient of phosphoric acid $(50 \mathrm{mmol} / \mathrm{L})$ and acetonitrile. The radiochemical purity of the tracer was $>99 \%$, and the average specific radioactivity \pm SD was $60 \pm 10 \mathrm{GBq} / \mu \mathrm{mol}$.

At the start of PET the 9-mL bolus of tracer solution was infused during $80 \mathrm{~s}$ into the right anterior cupital vein, according to the standard ${ }^{11} \mathrm{C}-\mathrm{MP} 4 \mathrm{~B}$ study protocol in our PET center. The average radioactivity $\pm \mathrm{SD}$ of the injected tracer was $707 \pm 34 \mathrm{MBq}$ in the body scans and $703 \pm 63 \mathrm{MBq}$ in the brain studies.

The dynamic body scans were fitted to cover the internal organs of the imaging region. The total scanning time of $40 \mathrm{~min}$ was divided into time frames of $8 \times 15 \mathrm{~s}, 6 \times 30 \mathrm{~s}, 5 \times 180 \mathrm{~s}$, and $4 \times 300 \mathrm{~s}$ - thus, adding up to 23 frames. In the brain scans the data were acquired for 60 min with time frames of $1 \times 30 \mathrm{~s}, 4 \times 15 \mathrm{~s}, 5 \times 30 \mathrm{~s}, 2 \times 60 \mathrm{~s}, 2 \times$ $120 \mathrm{~s}, 6 \times 300 \mathrm{~s}$, and $2 \times 600 \mathrm{~s}$, adding up to 22 frames.

Images were iteratively reconstructed with the ordered-subsets expectation maximization (OSEM) algorithm with 2 iterations and 28 subsets. Scatter correction, attenuation correction, random counts, and dead-time corrections were all incorporated into the reconstruction algorithm.

\section{Measurement of ${ }^{11} \mathrm{C}$ Radioactivity in Blood and Urine Samples}

Arterial blood samples were collected from the 28 elderly subjects during the brain PET scan, via a catheter inserted into the radial artery, because arterial blood time-activity data are necessary in the modeling of tracer kinetic in brain tissue. The procedure and measured time-activity curves are described in detail elsewhere (17). No blood samples were collected during the body scans to avoid unnecessary risks and inconvenience for the subjects.

Urine samples were collected after the body imaging scans and from 20 brain study participants. The fraction of injected radioactivity excreted to urine was quantified 14-90 min after the infusion of the ${ }^{11} \mathrm{C}-\mathrm{MP} 4 \mathrm{~B}$. Urinary samples of $2.5 \mathrm{~mL}$ were measured with a VDC404 dose calibrator (Veenra Instrumenten by Joure).

\section{Residence Times in Source Organs}

In our dosimetry procedure the residence times for source organs are determined with a 4-step procedure from the PET scan and the blood data. First, 2 summated images from each dynamic PET scan 
were calculated, one from the time frames of the first $2 \mathrm{~min}$ of the scan to visualize the organs with high blood flow and one from the frames of the last $25 \mathrm{~min}$ to detect the retention of the ${ }^{11} \mathrm{C}-\mathrm{MP} 4 \mathrm{~B}$. The source organs were defined by marking them manually as regions of interest (ROIs) on the summated images. The drawing was done by a single experienced operator and was reviewed subsequently by other investigators before the analyses. Then the ROIs were copied on the dynamic images, and the radioactivity concentration in the ROIs was plotted against time (time-activity curve).

In the second step, the time-activity curves were normalized to $1-\mathrm{MBq}$ injection (the denominator of the equation below) and to $70 \mathrm{~kg}$, the weight of the Fisher-Snyder phantom (19) used in the MIRD scheme:

$$
C^{\prime}(t)=C(t)\left(\frac{1}{A_{0}}\right)\left(\frac{W}{\bar{W}}\right)
$$

where $\mathrm{C}^{\prime}(\mathrm{t})$ is the normalized radioactivity concentration $(\mathrm{kBq} / \mathrm{mL})$, $\mathrm{C}(\mathrm{t})$ is the measured radioactivity concentration in the ROI $(\mathrm{kBq} / \mathrm{mL}), \mathrm{A}_{0}$ is the injected activity $(\mathrm{MBq}), \mathrm{W}$ is the weight of the subject $(\mathrm{kg})$, and $\bar{W}$ is the weight of the phantom reference $(70 \mathrm{~kg})$.

Third, exponential curve fitting was used to determine a timeactivity curve from the set of the normalized time-activity curves in each source organ. To choose the most appropriate fitting method, 4 different methods were compared in the liver ROI: 1-exponential, 2-exponential, and 3-exponential functions and an average curve of extrapolated ${ }^{11} \mathrm{C}$-decay function. After the last time frame, the timeactivity curve was assumed to continue in compliance with the fitted function of source organ radioactivity concentration.

Fourth, the cumulated radioactivity concentration for the source organs was determined as the area under the normalized average time-activity curve from 0 to infinity, except for the urinary bladder content from 0 to the voiding time. Total cumulated activity for organs was calculated by multiplying the cumulated activity concentration in the respective ROI by the volume of the organ in the Fisher-Snyder Reference Man.

\section{Radiation Dose Calculations}

Accumulated radioactivity in the remainder of the body, $A_{R B}$, was calculated with the equation:

$$
\bar{A}_{R B}=A_{0} \int_{0}^{T} e^{-\ln (2) / T_{\frac{1}{2}} t} d t+A_{T} \int_{T}^{\infty} e^{-\ln (2) / T_{\frac{1}{2}} t} d t-\sum_{i} A_{i},
$$

where $A_{0}$ is the injected dose, $A_{T}$ is the injected dose minus the excreted activity, and $A_{i}$ is the activity in the measured source organ. The excreted activity was estimated by an empiric formula of exponential in-growth fitted to the postscan urinary samples:

$$
\mathrm{A}_{\mathrm{B}}\left(1-\mathrm{e}^{-\mathrm{bt}}\right),
$$

where $A_{B}$ is the excretion fraction of the injected dose in the urine, $b$ is the rate coefficient for clearance, and $t$ is the time (20). In the fitting procedure, $A_{B}$ was adjusted to different values between $40 \%$ and $100 \%$ to fit the rate coefficient in the measured data. Cumulated activity of the bladder was determined by removing the physical decay from fitted curves and normalizing the data for 1-MBq injection of tracer activity. The average measured volume of the voided urine, $370 \mathrm{~mL}$, was used as volume of the urinary bladder in calculating total cumulated activity.

In the MIRD scheme, the mean absorbed dose (D) in target organ $\left(r_{k}\right)$ of the phantom from injected dose $A_{0}$ is calculated with the equation:

$$
D\left(r_{k}\right)=A_{0} \sum_{h} \frac{\bar{A}_{h}}{A_{0}} \sum_{i}\left[\left(\Delta_{i} \varphi \frac{\left(r_{k} \leftarrow r_{j}\right)_{i}}{m_{k}}\right)\right]
$$

where $\bar{A}_{h}$ is the cumulated activity in the source organ $\mathrm{h}, \mathrm{A}_{0}$ is the total activity injected into the patient, $\Delta_{\mathrm{i}}$ is the mean energy emitted per nuclear decay for the emission type $i, \varphi\left(r_{k} \leftarrow r_{j}\right)_{i}$ is the fraction of energy emitted in the source organ $\mathrm{h}$, which is absorbed in the target $\operatorname{organ} \mathrm{k}$, and $\mathrm{m}_{\mathrm{k}}$ is the mass of the target organ (16).

Residence time $\tau$ is the quotient of cumulated activity in the organ and total injected activity; $\tau=\overline{\mathrm{A}} / \mathrm{A}_{0}$. The quantity $\Sigma\left[\left(\Delta_{\mathrm{i}}\right.\right.$ $\left.\varphi\left(\mathrm{r}_{\mathrm{k}} \leftarrow \mathrm{r}_{\mathrm{j}}\right)_{\mathrm{i}}\right) / \mathrm{m}_{\mathrm{k}}$ ], which describes the physical characteristics of the radionuclide ${ }^{11} \mathrm{C}$ in the phantom model, was incorporated into a single variable $S\left(r_{k} \leftarrow r_{j}\right)$. The $S$ values for different radionuclides and phantoms can be obtained from a database (21); thus, the equation above is simplified into:

$$
\frac{\bar{D}\left(r_{k}\right)}{A_{0}}=\sum_{h} \tau_{h} S\left(r_{k} \leftarrow r_{h}\right) .
$$

The residence times of source organs were determined, and absorbed as well as effective doses were calculated with MIRDOSE3 software (Oak Ridge Associated Universities, Oak Ridge, TN) (22), according to the risk weight factors of Publication 60 of the International Commission on Radiation Protection (15).

\section{Comparison of DOSE Method with Simulated Whole-Body Scan Approach}

As described earlier, the residence time is the integral of the exponential function fitted to the measured time-activity data. In our DOSE method, the time-activity data are acquired for each source organ throughout the imaging, whereas, in the whole-body scan approach, the source organ is inside the FOV only in a few bed positions. In the whole-body studies, the FOVs, the number of bed positions, as well as the duration of time frames vary considerably (23-33).

We compared the 2 different acquisition procedures for residence time estimation. The simulation is done on the liver timeactivity curve, as the liver is a homogeneous and a relatively large organ that is well visualized in the ${ }^{11} \mathrm{C}$-MP4B PET images. The DOSE method requires at least 6 healthy volunteers or patients-3 for thorax and 3 for abdominal region scans. The whole-body procedure provides fewer experimental observations for each source organ. The number of subjects in published studies has been between 1 and 6 . To compare the estimates for absorbed doses between the whole-body scan approach and the DOSE method, we simulate whole-body data acquisition methods used in ${ }^{11} \mathrm{C}$ dosimetry studies $(23,26,28)$ with our fixed-bed data. We estimated the time frames of whole-body scanning in which liver was in the FOV and used only those time points in calculating the residence time.

\section{RESULTS}

We used the liver time-activity curve as an example for comparing the different methods in determining residence times. Different fitting methods yielded liver residence times of $0.047,0.041,0.040$, and $0.044 \mathrm{~h}$ with 1 -exponential, 2-exponential, and 3-exponential, and the average curve of extrapolated ${ }^{11} \mathrm{C}$-decay fitting functions, respectively. By visual inspection, the 2-exponential fitting was observed to 
give the closest match to the data and was used in calculating the residence times for source organs.

In line with the previously published whole-body ${ }^{11} \mathrm{C}$ MP4B summated image (17) and tissue-specific expression of the BCHE gene (http://t1dbase.org/page/GeneOverview/ display/gene_id/590), the organs that were easily visualized in the summated images were liver, urinary bladder, kidneys (renal cortex), upper large intestine, trabecular bone, salivary glands, and heart wall. The time-activity curves for kidneys, liver, muscle tissue, and salivary glands are illustrated in Figure 1.

The urinary excretion of ${ }^{11} \mathrm{C}-\mathrm{MP} 4 \mathrm{~B}$ was $5 \%-45 \%$ within the first $90 \mathrm{~min}$ after the injection of the tracer. Figure 2 illustrates the relative excreted ${ }^{11} \mathrm{C}$ activity in the urine- that is, the quotient of the measured activities $(n=27)$ of the total injected activity. The graph suggests that up to $60 \%$ of the injected dose is excreted via the urinary pathway, and this clearance is relatively rapid with $30 \%$ of the tracer excreted $60 \mathrm{~min}$ after injection - that is, at the end of the regular scan protocol in the brain studies with the tracer.

The residence times of the 14 source organs are given in Table 1. The residence times were calculated assuming no postscan urinary bladder voiding. The estimates of absorbed doses in target organs for an adult weighting $70 \mathrm{~kg}$ are given in Table 2. The highest absorbed doses were found in the urinary bladder $(0.019 \mathrm{mGy} / \mathrm{MBq})$ and the renal cortex $(0.014 \mathrm{mGy} / \mathrm{MBq})$. The effective dose was estimated to be $0.0042 \mu \mathrm{Sv} / \mathrm{MBq}$.

Calculating the residence times with 1- or 2-h voiding time - that is, assuming that the urinary bladder is voided 60 or $120 \mathrm{~min}$ after the injection-yielded similar estimates for absorbed doses in target organs than those with no voiding assumed, except for urinary bladder wall and uterus. For urinary bladder wall, a 1-h voiding time yielded an absorbed dose of $0.013 \mathrm{mGy} / \mathrm{MBq}$ and a 2 -h voiding time yielded $0.019 \mathrm{mGy} / \mathrm{MBq}$. For uterus, the absorbed doses were 0.0033 $\mathrm{mGy} / \mathrm{MBq}$ with a 1 -h voiding time and $0.0035 \mathrm{mGy} / \mathrm{MBq}$ with

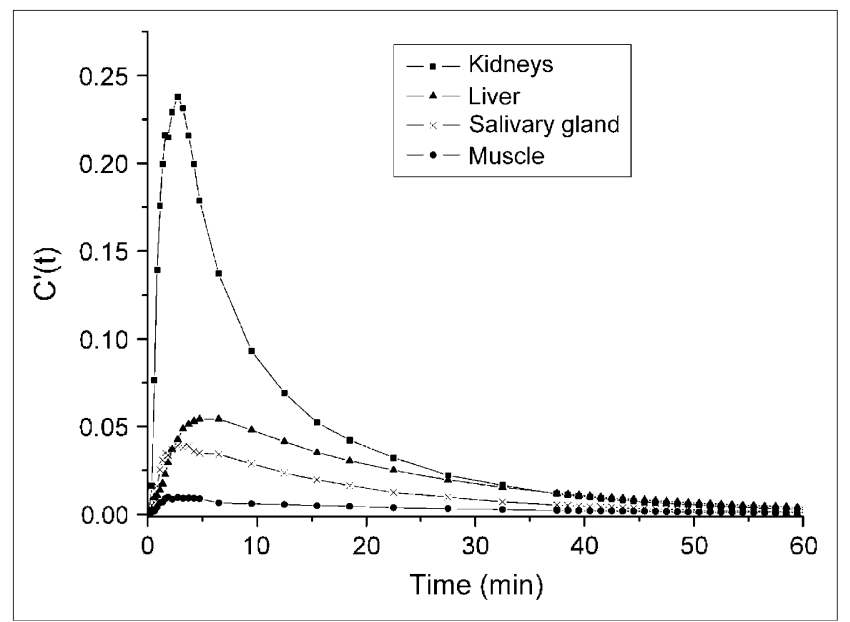

FIGURE 1. Normalized time-activity curves in kidneys, liver, muscle tissue, and salivary glands by 2-exponential fitting.

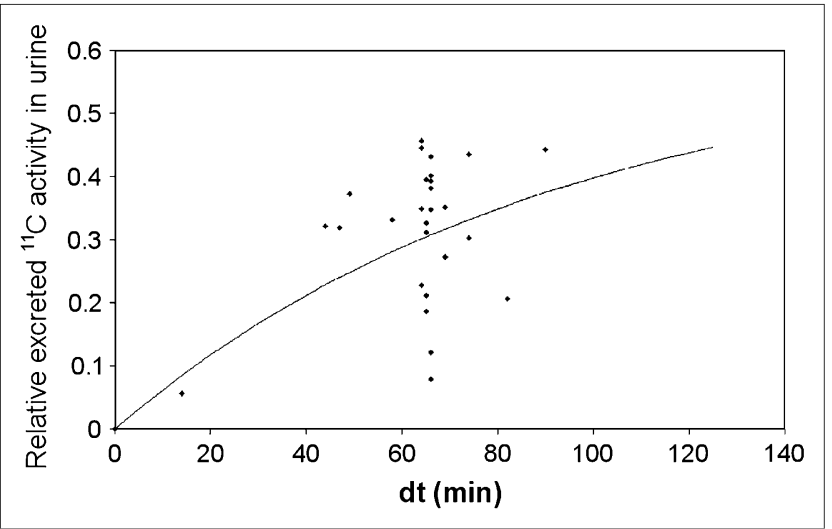

FIGURE 2. Empiric formula of exponential in-growth fitted on ${ }^{11} \mathrm{C}-\mathrm{MP} 4 \mathrm{~B}$ urine samples.

a 2 -h voiding time. With a 1 -h voiding time, the effective dose was estimated to be $0.0041 \mu \mathrm{Sv} / \mathrm{MBq}$ and with a $2-\mathrm{h}$ voiding time it was estimated to be $0.0042 \mu \mathrm{Sv} / \mathrm{MBq}$ - that is, similar to the effective dose estimated assuming no postscan voiding.

In comparing the DOSE method with the simulated wholebody scanning approach, the DOSE method yielded a liver residence time of $0.0411 \mathrm{~h}$ using the 2 -exponential fitting. We estimated that in the procedure used by Cropley et al. (23) and Lu et al. (26) liver was in the FOV in the third and fourth bed positions in each of 14 frames. By using corresponding time points from our data, the liver residence time would have been $0.0444 \mathrm{~h}$. Simulating the procedure of Parsey et al. (28) similarly (third and fourth bed positions, 5 frames) would yield a liver residence time of $0.0426 \mathrm{~h}$.

\section{DISCUSSION}

Because of the rapid clearance of ${ }^{11} \mathrm{C}-\mathrm{MP} 4 \mathrm{~B}$ and the short half-life of ${ }^{11} \mathrm{C}$, the different postscan urinary bladder voiding protocols gave similar estimates of absorbed doses, except in organs in a small pelvis. Assuming no postscan voiding gave

TABLE 1

Measured Residence Times in Source Organs of ${ }^{11} \mathrm{C}-\mathrm{MP} 4 \mathrm{~B}$

\begin{tabular}{lc}
\hline \multicolumn{1}{c}{ Source organ } & Residence time $(\mathrm{h})$ \\
\hline Brain & 0.018 \\
\hline Upper large intestine & 0.008 \\
Heart contents & 0.001 \\
Heart wall & 0.003 \\
Kidneys & 0.014 \\
Liver & 0.041 \\
Lungs & 0.006 \\
Muscle & 0.113 \\
Red bone marrow & 0.015 \\
Cortical bone & 0.068 \\
Trabecular bone & 0.007 \\
Urinary bladder content & 0.025 \\
Rest of body & 0.170 \\
\hline
\end{tabular}


TABLE 2

Absorbed Doses of ${ }^{11} \mathrm{C}-\mathrm{MP} 4 \mathrm{~B}$ to Target Organs in $70-\mathrm{kg}$ Reference Man

\begin{tabular}{|c|c|}
\hline Target organ & $\begin{array}{l}\text { Absorbed dose } \\
\text { (mGy/MBq) }\end{array}$ \\
\hline Adrenals & 0.0032 \\
\hline Brain & 0.0047 \\
\hline Breasts & 0.0020 \\
\hline Gallbladder wall & 0.0035 \\
\hline Lower large intestine wall & 0.0030 \\
\hline Small intestine & 0.0031 \\
\hline Stomach & 0.0027 \\
\hline Upper large intestine wall & 0.0066 \\
\hline Heart wall & 0.0034 \\
\hline Kidneys & 0.0137 \\
\hline Liver & 0.0078 \\
\hline Lungs & 0.0027 \\
\hline Muscle & 0.0022 \\
\hline Ovaries & 0.0031 \\
\hline Pancreas & 0.0031 \\
\hline Red marrow & 0.0039 \\
\hline Bone surfaces & 0.0046 \\
\hline \multicolumn{2}{|l|}{ Salivary glands } \\
\hline Parotid glands & 0.0073 \\
\hline Submandibular glands & 0.0019 \\
\hline Skin & 0.0020 \\
\hline Spleen & 0.0027 \\
\hline Testes & 0.0024 \\
\hline Thymus & 0.0023 \\
\hline Thyroid & 0.0024 \\
\hline Urinary bladder wall & 0.0186 \\
\hline Uterus & 0.0035 \\
\hline Total body & 0.0028 \\
\hline Effective dose (mSv/MBq) & 0.0042 \\
\hline
\end{tabular}

the most conservative estimate of the effective dose, and, thus, the assumption was used in calculating the absorbed doses.

When assessing the safety of a tracer, it is compared with the theoretic maximum effective dose calculated from the generic biokinetic model, described in Addendum 5 to ICRP Publication 53 (34), which for the ${ }^{11} \mathrm{C}$-tracers is 11.0 $\mu \mathrm{Sv} / \mathrm{MBq}$. The ${ }^{11} \mathrm{C}$-labeled tracers in clinical use have relatively low effective doses, varying between 4.2 and 7.0 $\mu \mathrm{Sv} / \mathrm{MBq}$, except for ${ }^{11} \mathrm{C}-\mathrm{WAY} 100635$, which causes an overall radiation exposure of $14.1 \mu \mathrm{Sv} / \mathrm{MBq}(23-33,35)$. In comparison with other ${ }^{11} \mathrm{C}$-tracers (Table 3 ), the effective dose for ${ }^{11} \mathrm{C}-\mathrm{MP} 4 \mathrm{~B}$ is one of the lowest and is well below the dose estimated by the generic model.

With the 740-MBq standard dose in our ${ }^{11} \mathrm{C}-\mathrm{MP} 4 \mathrm{~B}$ studies, the radiation burden is equivalent to $3.11 \mathrm{mSv}$, or 3.5 brain CT scans (effective dose for adult brain CT scan is approximately $0.9 \mathrm{mSv}(36)$ ). With $500 \mathrm{MBq}$ of injected radioactivity, the ${ }^{11} \mathrm{C}$-MP4B PET results in an effective dose of $2.10 \mathrm{mSv}$ (equivalent to 2.3 brain $\mathrm{CT}$ scans), ${ }^{11} \mathrm{C}$-raclopride results in an effective dose of $3.3 \mathrm{mSv}$ (3.6 brain CT scans), and, as an extreme example, ${ }^{11} \mathrm{C}$-WAY 100635 results in an effective dose of $7.05 \mathrm{mSv}$ ( 7.8 brain CT scans). Therefore, it is important to estimate the radiation burden of each tracer separately instead of using the generic effective dose of the radionuclide. To our
TABLE 3

Effective Doses of ${ }^{11} \mathrm{C}$-Labeled PET Tracers in Humans

\begin{tabular}{|c|c|c|}
\hline Radioligand & $\begin{array}{l}\text { Effective dose } \\
(\mu \mathrm{Sv} / \mathrm{MBq})\end{array}$ & Reference \\
\hline${ }^{11} \mathrm{C}-\mathrm{MP} 4 \mathrm{~B}$ & 4.2 & \\
\hline${ }^{11} \mathrm{C}$-Glucose & 4.3 & (25) \\
\hline${ }^{11} \mathrm{C}-\mathrm{PIB}$ & 4.7 & (35) \\
\hline${ }^{11} \mathrm{C}-$ Methoxyprogabidic acid & 4.8 & (31) \\
\hline${ }^{11} \mathrm{C}$-Acetate & 4.9 & (32) \\
\hline${ }^{11} \mathrm{C}-$ Methionine & 5.3 & (24) \\
\hline${ }^{11} \mathrm{C}-\mathrm{NNC} 112$ & 5.7 & (23) \\
\hline${ }^{11} \mathrm{C}-\mathrm{PE} 2 \mathrm{I}$ & 6.4 & (30) \\
\hline${ }^{11} \mathrm{C}$-Raclopride & 6.5 & (33) \\
\hline${ }^{11} \mathrm{C}-$ Raclopride & 6.7 & (29) \\
\hline${ }^{11} \mathrm{C}-$ Mirtazapine & 6.8 & $(27)$ \\
\hline${ }^{11} \mathrm{C}-\mathrm{DASB}$ & 7.0 & (26) \\
\hline${ }^{11} \mathrm{C}-\mathrm{WAY} 100635$ & 14.1 & (28) \\
\hline
\end{tabular}

knowledge, no dosimetry studies on radioligands structurally similar to ${ }^{11} \mathrm{C}-\mathrm{MP} 4 \mathrm{~B}$ have been published.

For an accurate estimation of the effective dose for ${ }^{11} \mathrm{C}$ MP4B, special attention was given to a reliable selection and outlining of the source organs. Red marrow was selected as a source organ, even though the marrow in the iliac cristae was not a hot area in the summated images, as the tissue is sensitive to the adverse effects of radiation. Salivary glands were selected as source organs because they have been observed to accumulate the tracer (17). The myocardial ROIs were drawn on the outer parts of the heart to avoid spillover from the blood and the red bone marrow ROIs on the internal parts of the pelvic cristae to avoid spillover from the cortical bone. The brain ROI is a sum of ROIs outlined in the cerebral cortex, striatum, cerebellum, and brain stem, the areas where the highest enzyme activities in the central nervous system have been observed (13). Because of the rapid excretion of the tracer via kidneys, renal pelvis and the ureters were also visible in the summated images. Using the urinary bladder content as a source organ also covers the radiation exposure for these structures.

The highest activity concentrations were measured in the urinary bladder, kidneys, large intestine, and liver. In line with this, the highest absorbed doses were measured in the urinary bladder wall, large intestine wall, kidneys, and liver. Yet, the main sources of radiation were-due to their large volume - the body outside specified regions (remainder of the body), muscle tissue, and cortical bone. The exposure from the cortical bone might also be partially due to the fact that the ROIs for the tissue were outlined in the vertebral bodies, in which the activity was higher than that observed elsewhere in the skeleton.

Cholinergic nerves are known to be abundant outside the central nervous system-for example, in cardiac neurons $(37,38)$ and in urinary and gastrointestinal tracts. The clinical side effects of the cholinesterase inhibitors have been suggested to be primarily due to the BuChE activity outside the brain. Nevertheless, the distribution of the enzyme in the human body has not, to our knowledge, been characterized. 
Although the clinical radiation safety of the tracer is the main outcome of this study, the results also approximate the wholebody BuChE activity, along with the biodistribution study published earlier (17). Nevertheless, the exact enzyme activity cannot be determined from these results, as the residence times are affected also by blood flow, tracer uptake, and excretion.

When comparing the DOSE method with the simulated whole-body imaging approach, the methods gave roughly similar residence times for liver. As the whole-body studies require fewer PET scans, this method might be most appropriate for ${ }^{11} \mathrm{C}$-radioligands with rapid clearance, especially if short time frames (approximately $15 \mathrm{~s}$ per bed position) are chosen. Otherwise, the whole-body images might not give a sufficient number of data points for validly fitting the decay function on the observed data. In addition, in the DOSE method, the ROIs drawn on the summated images are valid over all time frames.

The ROIs cover a representative range of source organs, and the total absorbed dose is estimated by multiplying the ROI concentration with the organ volume. This gives more conservative estimates of the absorbed doses than measuring the whole-organ radioactivity in the whole-body imaging approach. With precise subject positioning, the same source organs are covered in the DOSE method as are measured in whole-body procedures, especially if additional brain studies are available and urine measurements are recorded.

\section{CONCLUSION}

${ }^{11} \mathrm{C}-\mathrm{MP} 4 \mathrm{~B}$ causes less radiation burden than other studied ${ }^{11} \mathrm{C}$-labeled PET tracers. No intolerably high absorbed doses were observed in critical organs. With $740 \mathrm{MBq}$ of injected radioactivity, the radiation burden is equivalent to $3.11 \mathrm{mSv}$. This would allow multiple PET examinations to be performed on the same subject per year. When comparing the DOSE method with the simulated whole-body imaging approach, the methods gave roughly similar results.

\section{ACKNOWLEDGMENTS}

We thank the medical laboratory technologists and radiographers of Turku PET Centre for skillful assistance and cooperation. We also thank the staff of the Turku University radiochemistry laboratory for the production and delivery of the tracer. This study was financially supported by clinical grants of Turku University Hospital.

\section{REFERENCES}

1. Francis PT, Perry EK. Neurochemical pathology of cholinergic systems in neurodegenerative and neurodevelopmental disorders. In: Giacobini E, Pepeu G, eds. The Brain Cholinergic System in Health and Disease. Oxon, U.K.: Informa Health Care; 2006:59-74.

2. Ringman JM, Cummings JL. Current and emerging pharmacological treatment options for dementia. Behav Neurol. 2006;17:5-16.

3. Ballard CG. Advances in the treatment of Alzheimer's disease: benefits of dual cholinesterase inhibition. Eur Neurol. 2002;47:64-70.

4. Guillozet AL, Smiley JF, Mash DC, Mesulam MM. Butyrylcholinesterase in the life cycle of amyloid plaques. Ann Neurol. 1997;42:909-918.
5. Mesulam MM, Guillozet A, Shaw P, Quinn B. Widely spread butyrylcholinesterase can hydrolyze acetylcholine in the normal and Alzheimer brain. Neurobiol Dis. 2002;9:88-93.

6. Mesulam MM, Geula C. Butyrylcholinesterase reactivity differentiates the amyloid plaques of aging from those of dementia. Ann Neurol. 1994;36:722-727.

7. Moran MA, Mufson EJ, Gomezramos P. Cholinesterases colocalize with sites of neurofibrillary degeneration in aged and Alzheimers brains. Acta Neuropathol. 1994;87:284-292.

8. Perry EK, Perry RH, Blessed G, Tomlinson BE. Changes in brain cholinesterases in senile dementia of Alzheimer type. Neuropathol Appl Neurobiol. 1978;4:273-277.

9. Bohnen NI, Kaufer DI, Hendrickson R, et al. Cognitive correlates of alterations in acetylcholinesterase in Alzheimer's disease. Neurosci Lett. 2005;380:127-132.

10. Kaasinen V, Nagren K, Jarvenpaa T, et al. Regional effects of donepezil and rivastigmine on cortical acetylcholinesterase activity in Alzheimer's disease. J Clin Psychopharmacol. 2002;22:615-620.

11. Pappata S, Tavitian B, Traykov L, et al. In vivo imaging of human cerebral acetylcholinesterase. J Neurochem. 1996;67:876-879.

12. Rinne JO, Kaasinen V, Jarvenpaa T, et al. Brain acetylcholinesterase activity impairment and early Alzheimer's in mild cognitive disease. J Neurol Neurosurg Psychiatry. 2003;74:113-115.

13. Kuhl DE, Koeppe RA, Snyder SE, Minoshima S, Frey KA, Kilbourn MR. In vivo butyrylcholinesterase activity is not increased in Alzheimer's disease synapses. Ann Neurol. 2006;59:13-20.

14. Snyder SE, Gunupudi N, Sherman PS, et al. Radiolabeled cholinesterase substrates: in vitro methods for determining structure-activity relationships and identification of a positron emission tomography radiopharmaceutical for in vivo measurement of butyrylcholinesterase activity. J Cereb Blood Flow Metab. 2001; 21:132-143.

15. International Commission on Radiological Protection. Recommendation of the International Commission on Radiological Protection: Publication 60. Oxford, U.K.: Pergamon Press; 1990:4-11.

16. Howell RW, Wessels BW, Loevinger R. The MIRD perspective 1999. J Nucl Med. 1999;40(suppl):3S-10S

17. Roivainen A, Rinne J, Virta J, et al. Biodistribution and blood metabolism of 1-[ $\left[{ }^{11} \mathrm{C}\right]$ methyl-4-piperidinyl n-butyrate in humans: an imaging agent for in vivo assessment of butyrylcholinesterase activity with PET. J Nucl Med. 2004;45:2032-2039.

18. DeGrado TR, Turkington TG, Williams JJ, Stearns CW, Hoffman JM, Coleman RE. Performance characteristics of a whole-body PET scanner. J Nucl Med. 1994;35:1398-1406.

19. International Commission on Radiological Protection. Report of the Task Group on Reference Man. Oxford, UK.: Pergamon Press; 1975:325-327.

20. Graham MM, Peterson LM, Link JM, et al. Fluorine-18-fluoromisonidazole radiation dosimetry in imaging studies. $J$ Nucl Med. 1997;38:1631-1636.

21. Weber D, Eckerman KE, Dillman LT, Ryman JC. MIRD: Radionuclide Data and Decay Schemes. New York, NY: Society of Nuclear Medicine; 1989.

22. Stabin MG. MIRDOSE: personal computer software for internal dose assessment in nuclear medicine. J Nucl Med. 1996;37:538-546.

23. Cropley VL, Fujita M, Musachio JL, et al. Whole-body biodistribution and estimation of radiation-absorbed doses of the dopamine D-1 receptor radioligand C-11-NNC 112 in humans. J Nucl Med. 2006;47:100-104.

24. Deloar HM, Fujiwara T, Nakamura T, et al. Estimation of internal absorbed dose of L-[methyl-C-11]methionine using whole-body positron emission tomography. Eur J Nucl Med. 1998;15:629-633.

25. Graham MM, Peterson LM, Muzi M, et al. 1-[Carbon-11]-glucose radiation dosimetry and distribution in human imaging studies. J Nucl Med. 1998;39:1805-1810.

26. Lu JQ, Ichise M, Liow JS, Ghose S, Vines D, Innis RB. Biodistribution and radiation dosimetry of the serotonin transporter ligand C-11-DASB determined from human whole-body PET. J Nucl Med. 2004;45:1555-1559.

27. Marthi K, Hansen SB, Jakobsen S, Bender D, Smith SB, Smith DF. Biodistribution and radiation dosimetry of [N-rnethyl-C-11]mirtazapine, an antidepressant affecting adrenoceptors. Appl Radiat Isot. 2003;59:175-179.

28. Parsey RV, Belanger MJ, Sullivan GM, et al. Biodistribution and radiation dosimetry of C-11-WAY100635 in humans. J Nucl Med. 2005;46:614-619.

29. Ribeiro MJ, Ricard M, Bourgeois S, et al. Biodistribution and radiation dosimetry of [C-11]raclopride in healthy volunteers. Eur J Nucl Med Mol Imaging. 2005; 32:952-958.

30. Ribeiro MJ, Ricard M, Lièvre MA, et al. Whole-body distribution and radiation dosimetry of the dopamine transporter radioligand $\left[{ }^{11} \mathrm{C}\right] \mathrm{PE} 2 \mathrm{I}$ in healthy volunteers. Nucl Med Biol. 2007;34:465-470.

31. Santens P, De Vos F, Thierens H, et al. Biodistribution and dosimetry of carbon11-methoxyprogabidic acid, a possible ligand for GABA-receptors in the brain. J Nucl Med. 1998;39:307-310.

32. Seltzer MA, Jahan SA, Sparks R, et al. Radiation dose estimates in humans for C-11-acetate whole-body PET. J Nucl Med. 2004;45:1233-1236. 
33. Slifstein M, Hwang DR, Martinez D, et al. Biodistribution and radiation dosimetry of the dopamine D-2 ligand C-11-raclopride determined from human whole-body PET. J Nucl Med. 2006;47:313-319.

34. International Commission on Radiological Protection. Radiation doses to patients from radiopharmaceuticals: IRCP publication 53. Ann IRCP. 1987;18:149-150.

35. Scheinin NM, Tolvanen TK, Wilson IA, Arponen EM, Nagren KA, Rinne JO. Biodistribution and radiation dosimetry of the amyloid imaging agent ${ }^{11} \mathrm{C}$-PIB in humans. J Nucl Med. 2007;48:128-133.
36. Huda W, Vance A. Patient radiation doses from adult and pediatric CT. AJR. 2007; 188:540-546.

37. Darvesh S, MacDonald SE, Losier AM, Martin E, Hopkins DA, Armour JA. Cholinesterases in cardiac ganglia and modulation of canine intrinsic cardiac neuronal activity. J Auton Nerv Syst. 1998;71:75-84.

38. Darvesh S, Arora RC, Martin E, Magee D, Hopkins DA, Armour JA. Cholinesterase inhibitors modify the activity of intrinsic cardiac neurons. Exp Neurol. 2004; 188:461-470.

\section{Erratum}

The authors of "A Comparison of the Diagnostic Accuracy of ${ }^{18}$ F-FDG PET and CT in the Characterization of Solitary Pulmonary Nodules" (Fletcher et al. J Nucl Med. 2008;49:179-185) inadvertently omitted a listing of the contributors and contributing sites of the SNAP Investigative Group. The listing appears below.

\author{
Ann Arbor VAMC/University of Michigan \\ Charles Marn, MD \\ Lorraine Fig, MD \\ Milton Gross, MD (former) \\ Paul Shreve, MD (former) \\ Gwendoline Chalam, MPH \\ Kalyani Adusumilli, MPH (former) \\ Atlanta VAMC/Emory University \\ Naomi Alazraki, MD \\ Raghuveer Halkar, MD \\ John Hoffman, MD (former) \\ Sean Riggin \\ Lee Ann Zavosky (former)
}

VA Western New York Health Care System (Buffalo, NY)

Syed Husain, MD

Elongia Farrell

Durham VAMC/Duke University

R. Edward Coleman, MD

Kathy Willis

Sherri Pennell (former)

Indianapolis VAMC/Indiana University (IUPUI)

Donald Schauwecker, MD

Kathy Carlson

Madison VAMC/University of Wisconsin

Scott Perlman, MD

Lyn Thet, MD

Mary Falls, RN, CRNC

VA Palo Alto Health Care System

George Segall, MD

Maureen Osen

Julie Loero (former)

St. Louis VAMC/Saint Louis University

Jeffrey Chenoweth, MD

Val Lowe, MD (former)

Shohreh Jamabaladi-Majidi, DMD, MPH

Keith Kotansky (former)

VA Puget Sound Health Care System (Seattle Division)/

University of Washington

Arnold Jacobson, MD

Michael Graham, MD, PhD (former)

Jeff Coppersmith (former)

Jean Hadlock (former)

West Los Angeles VAMC

Mark Mandelkern, MD

Silverio Santiago, MD

John Zhang, MD

Karen Shon (former)
VA Palo Alto Cooperative Studies Program Coordinating Center

Kelvin Lee, PhD

Maryann Boeger

Carol Kerner (former)

Lan Zhao

Bor-Ming Ou (former)

Andres Busette

Mara Nguyen (former)

Linh Luu (former)

Jeron Talbott

Rodney Paris (former)

Independent Research Readers Panel

James Glockner, MD—Mayo Clinic

Michael Graham, MD, PhD-University of Iowa

Naresh Gupta, MD—American Radiology Services, Inc.

Jud Gurney, MD—University of Nebraska

Val Lowe, MD-Mayo Clinic

Paul Stark, MD—University of California at San Diego/ San Diego VAMC

SNAP Chair's Office

Study Chair

James W. Fletcher, MD-University of Indiana (IUPUI)

(formerly of the St. Louis VA Medical Center)

Study Co-Chair

George Segall, MD_VA Palo Alto Health Care System

Project Coordinator

Steven Kymes, PhD, MHA-Washington University School of

Medicine (formerly of the St. Louis VA Medical Center)

\section{SNAP Executive Committee}

James W. Fletcher, MD—Study Chair

George Segall, MD—Study Co-Chair

Naomi Alazraki, MD (Coincidence Imaging Substudy Chair)

Paul Barnett, PhD (Economic Substudy Chair)

R. Edward Coleman, MD

Kelvin Lee, $\mathrm{PhD}$

Val Lowe, MD

Charles Marn, MD

Data and Safety Monitoring Board

Frank Papatheofanis, MD, PhD (Chair)—University of California at San Diego

Mark Espeland, PhD—Wake Forest University

Claudia Henschke, MD, PhD—New York University, Cornell Medical School

Heinrich R. Schelbert, MD, PhD-University of California at Los Angeles 